\title{
COMPARATIVE STUDY ON USE OF PLATELET-RICH PLASMA ALONE AND IN COMBINATION WITH ALPHA-TRICALCIUM PHOSPHATE CEMENT FOR BONE REPAIR IN RATS
}

Alessandra Deise Sebben', Gabriela Hoff ${ }^{2}$, Caroline Peres Klein ${ }^{3}$, Thiago Alexi de Freitas ${ }^{4}$, Camilla Assad ${ }^{4}$, Luís Alberto dos Santos ${ }^{5}$, Jefferson Braga Silva ${ }^{6}$

\begin{abstract}
Objectives: To evaluate the effect of alpha-tricalcium phosphate $(\alpha-$ TCP) cement combined with platelet-rich plasma (PRP) on osteogenesis, and to compare the results with use of PRP alone. Methods: A bilateral defect was produced in rat femurs and was filled with one of two types of treatments (PRP or $\alpha$-TCP + PRP). The outcomes were evaluated after four and eight weeks. Radiographic images provided values for the lesion area, and histology (picrosirius staining) indicated the area of new bone formation. Results: The means relating to the lesion area of the $\alpha$-TCP + PRP group $\left(2.64 \pm 2.07\right.$ and $1.91 \pm 0.93 \mathrm{~mm}^{2}$, after four and eight weeks, respectively) showed numerically better
\end{abstract}

but non-significant results $(\mathrm{p}>0.05)$ than those seen in the PRP group $\left(5.59 \mathrm{~mm}^{2} \pm 2.69\right.$ and $3.23 \pm 1.46 \mathrm{~mm}^{2}$, after four and eight weeks, respectively). The mean new bone formation rates were $62.7 \% \pm 12.1$ and $79.01 \% \pm 6.25$ in the PRP group, and $73.3 \% \pm 12.7$ and $85.86 \% \pm 10.45$ in $\alpha$-TCP + PRP group, after four and eight weeks, respectively $(\mathrm{p}>0.05)$. Conclusion: The data from this study suggest that treatment with $\alpha$-TCP cement combined with PRP does not show any significant difference in comparison with PRP alone. However, there is a possible early effect on bone regeneration when the two biomaterials are applied together.

Keywords - Animals; Bone Substitutes; Growth Factor

\section{INTRODUCTION}

Musculoskeletal injuries are considered to be one of the main causes of severe pain and morbidity worldwide. This damage often causes physical incapacitation and substantially diminishes the quality of life of individuals affected by such injuries ${ }^{(1,2)}$. Sports activities and traffic accidents are the main agents of these injuries, which have a large socioeconomic impact and have high financial costs ${ }^{(2)}$.

Reconstruction of large bone segments consequent to pathological events such as trauma, inflammation and surgical treatment of tumors continues to be an important clinical problem. Injured bone tissue has the capacity to return to its original structure ${ }^{(3)}$, but if the defect consists of loss of bone mass, the regeneration becomes limited. Among the therapeutic alternatives most used for reconstructing large bone lesions are transplantation of bone grafts (autologous, homologous or heterologous) and implantation of different biomaterials ${ }^{(4)}$.

Autologous grafts are characterized as having high osteoinductive capacity, but they present disadvantages such as the need for a second surgical intervention to remove the graft, the possibility of morbidity at the site and a scarcity of donor tissue ${ }^{(5)}$. With the aim of assisting in accelerating the modulation of repairs

1 - MSc in Health Sciences. Pontifical Catholic University of Rio Grande do Sul (PUCRS), Porto Alegre, RS, Brazil.

2 - PhD in Nuclear Biosciences and Medical Physics. Professor at the Pontifical Catholic University of Rio Grande do Sul (PUCRS), Porto Alegre, RS, Brazil.

3 - BSc in Biomedicine, Feevale University, Novo Hamburgo, RS, Brazil.

4 - MD. Pontifical Catholic University of Rio Grande do Sul (PUCRS), Porto Alegre, RS, Brazil.

5 - Professor, Coordinator of the Biomaterials Laboratory and Head of the Department of Materials Engineering, Federal University of Rio Grande do Sul (UFRGS), Porto Alegre, RS, Brazil.

6 - Full Professor, Unifesp; Professor in the Department of Surgery, FAMED, Pontifical Catholic University of Rio Grande do Sul (PUCRS); Heads of the Hand and Reconstructive Microsurgery Clinic, Hospital São Lucas, PUCRS, Porto Alegre, RS, Brazil.

Work performed in the Medical Skills and Surgical Research Laboratory, PUCRS, and in the Biomaterials Laboratory, UFRGS.

Correspondence: Av. Ipiranga 6690, prédio 64, Partenon, 90610-000 Porto Alegre, RS, Brazil. E-mail: adsebben@gmail.com

Work received for publication: May 25, 2011; accepted for publication: July 31, 2011.

The authors declare that there was no conflict of interest in conducting this work 
to injured bone, and to overcome the disadvantages of autologous grafts, inorganic bone substitutes have been widely applied as biomaterials in orthopedics and dentistry ${ }^{(6)}$. Among these inorganic materials, calcium phosphate cements such as alpha-tricalcium phosphate $(\alpha-$ TCP) cement are constantly used by orthopedic and oral-maxillofacial surgeons because of their characteristics of biocompatibility and osteoconductivity. These cements are also considered to be biodegradable and bioactive materials, since they establish chemical bonds with the bone tissue, which facilitates proliferation of fibroblasts, osteoblasts and other bone cells ${ }^{(7)}$.

From tissue engineering, it has been proposed that a complex of interactions involving osteoprogenitor cells, osteoinductive mediators and osteoconductive matrixes would be the ideal alternative for restoration of both soft and hard tissues ${ }^{(8)}$. Knowing that inductive proteins such as growth factors regulate cell events that stimulate bone neoformation, combined application of these with alpha-phosphate cement might be a promising strategy for stimulating osteogenesis in cases of difficult-to-repair bone damage.

Platelet-rich plasma (PRP), which is characterized as a volume of plasma with a platelet concentration three to eight times greater than physiological levels ${ }^{(9-11)}$, is an autologous source of growth factors and forms a therapeutic alternative for application together with bone substitutes such as $\alpha$-TCP cement. According to Marx ${ }^{(12)}$, PRP releases a set of seven trophic factors for which the carrier is blood coagulum. These factors include the three isoforms of platelet-derived growth factor (PDGF), alpha and beta transformation growth factors (TGF- $\alpha$ and TGF- $\beta$ ), vascular endothelial growth factor (VEGF) and epithelial growth factor (EGF).

The proteins released by the platelets create a microenvironment favorable towards tissue healing, induction of chemotaxis, cell proliferation and differentiation and tissue residue removal. PRP also contains proteins such as fibrin, fibronectin and vitronectin, which act as cell adhesion molecules, thus favoring osteoconduction, as well as being essential in forming bone matrix ${ }^{(13-15)}$. Some investigators have used PRP in association with other biomaterials in an attempt to obtain better results in bone repairs than are achieved through PRP use alone ${ }^{(16-18)}$.

Within this context, the aim of this study was to compare the effect of PRP, as an autologous source of growth factors, on osteogenesis when applied separately or in combination with granulated $\alpha$-TCP cement, to cavity defects in rats.

\section{MATERIAL AND METHODS}

\section{Animals and experimentation groups}

The present study was approved by the Ethics Committee for Animal Use (CEUA) of the Pontifical Catholic University of Rio Grande do Sul. Fourteen adult male Wistar rats (Rattus norvegicus) of approximate body weight 250 grams were used. Two of them were used as blood donors to obtain PRP. The remaining 12 animals were used to conduct the experiment and were randomly distributed into two groups with different assessment periods (four and eight weeks).

\section{Obtaining of platelet-rich plasma (PRP)}

Two adult male rats were used as blood donors, after they had been anesthetized intraperitoneally using a solution formed by ketamine hydrochloride $(50 \mathrm{mg} / \mathrm{kg})$ and chlorpromazine hydrochloride $(5 \mathrm{mg} / \mathrm{kg})$ in the same syringe. Six milliliters of blood were drawn from the carotid artery of each animal and were immediately transferred to tubes containing a solution of acid citrate dextrose-A (ACD-A), in order to avoid coagulation.

The blood was subjected to two centrifugations ( $200 \mathrm{~g}$ for 10 minutes and $400 \mathrm{~g}$ for 10 minutes), in a hematological centrifuge (CELM - LS 3 Plus) in the Clinical Pathology Laboratory of Hospital São Lucas, PUCRS (HLS), in accordance with an adapted protocol ${ }^{(19)}$.

After the second centrifugation, platelet-poor plasma (PPP) was obtained in the upper part of the tube, PRP in the intermediate zone and a small button of red blood cells at the bottom of the tube. The PPP was removed from the tube and discarded. The PRP was activated using a mixture of calcium chloride $\left(\mathrm{CaCl}_{2}\right)$ and thrombin $(600 \mathrm{IU} / \mathrm{mL}$ of thrombin in $1 \mathrm{~mL}$ of 5.9 $\mathrm{mg} / \mathrm{mL} \mathrm{CaCl}{ }_{2}$; Aventis Behring, São Paulo, Brazil) in the proportions of 1:2 of PRP. The PRP gel was applied either separately in the right cavity or mixed with granulated $\alpha$-TCP cement in the left cavity of each animal, immediately after the bone lesions had been produced, in quantities of $100 \mu \mathrm{L}$.

\section{Platelet counting}

The numbers of platelets in the normal blood of the rats and in the PRP samples were quantified using an 
automated cell counter (SYSMEX, model XT 1800, Roche $^{\circledR}$ ). This was done in the Clinical Pathology Laboratory of Hospital São Lucas, PUCRS, in accordance with the manufacturer's specifications.

\section{Synthesis of granulated $\alpha$-TCP cement}

The granulated $\alpha$-TCP cement used in this study was synthesized and supplied by the Biomaterials Laboratory (BIOMAT) of the Federal University of Rio Grande do Sul (UFRGS). Its composition was $85 \% \alpha$-TCP and $15 \%$ semi-hydrated calcium sulfate. As recommended by the manufacturer ${ }^{(20)}$, the cement was mixed with a liquid containing $2.5 \% \mathrm{Na}_{2} \mathrm{HPO}_{4}$ (accelerator) until reaching the desired consistency. The granule size was between 150 and $300 \mu \mathrm{m}$ and the quantity applied to each animal was $50 \mathrm{mg}$.

\section{Anesthetic and surgical procedures}

The surgical procedures were performed at the Medical Skills and Surgical Research Laboratory of the School of Medicine of PUCRS.

Anesthesia was administered in accordance with the protocol mentioned earlier. After the surgical access area on both femurs (right and left) had been shaved, the animals were positioned in lateral decubitus and an incision was made in the skin of the lateral face of the thigh, of length $1.5 \mathrm{~cm}$. The vastus lateralis and biceps femoris muscles were divulsed and the femur was exposed. In the anterolateral portion of the proximal diaphysis of the femur, a cavity defect was created using a Carbide drill bit, number 8 , with a high-rotation motor, with constant irrigation using sterile physiological solution. The lesion was produced by the same surgeon in all the animals ( $5 \mathrm{~mm} \times 2 \mathrm{~mm}$ ), with sufficient depth to expose the medullary cavity of the femur ${ }^{(21)}$, taking special care not to compromise the medial cortical bone, thereby diminishing the possibility of fracturing of the femur after the operation (Figure 1). The cavity in the right femur was filled with PRP alone, while the cavity in the left femur was filled with PRP plus granulated $\alpha$-TCP cement.

Subsequently, the fascia lata was brought together using a Prolene 5-0 suture (Ethilon ${ }^{\circledR}$, Johnson \& Johnson, Brazil), and the skin was sutured using mononylon 4-0 thread (Ethilon ${ }^{\circledR}$, Johnson \& Johnson, Brazil).

\section{Postoperative period}

The rats were kept in individual cages after the surgery, in the same vivarium from which they originated. Analgesia was applied, consisting of ketoprofen,

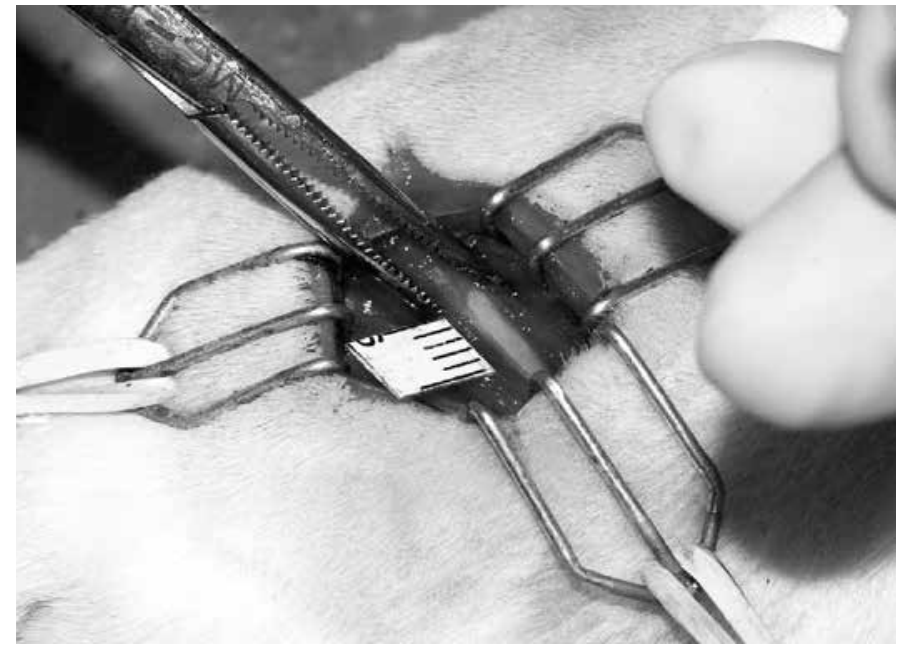

Figure 1 - Exposure of rats' femurs for creation of cavity lesions of length $5 \mathrm{~mm}$.

intraperitoneally at a dose of $5 \mathrm{mg} / \mathrm{kg}$. The animals were monitored during the immediate postoperative period by a surgical team.

\section{Radiographic analyses}

On the day before sacrificing the animals (either four or eight weeks after the operation), radiographs on all the femurs were produced. To obtain the images, the animals were anesthetized and positioned in ventral decubitus, with the aid of the Mamomat 3000 mammography apparatus $\left(\right.$ Siemens $\left.{ }^{\circledR}\right)$. Specific image transducers for mammography (Image Plate, Fuji ${ }^{\circledR}$ ) were used.

The radiographic technique consisted of a Mo-Mo target-trail combination, tube accelerator tension of 28 $\mathrm{kVp}$ and load of $14 \mathrm{mAs}$. The technique was adjusted so as to view the critical lesions in the rats' femurs. The digitized radiographic images were evaluated by a properly capacitated experienced examiner, with the aid of the Image J software. To ensure and test the reproducibility of the image analysis process, a standard operational procedure was developed and the intraclass correlation coefficient was applied to two groups: one group without experience of this type of analysis, and no familiarity with the Image J software or with the characteristics of the lesions; and another group consisting of capacitated and experienced individuals. The coefficient values taken as the reference were: ICC $<0.4$ (poor); $0.4 \leq$ ICC $<0.75$ (satisfactory); and ICC $\geq 0.75$ (excellent).

At the time of evaluating each lesion, the area of the lesion was determined $\left(\mathrm{mm}^{2}\right)$ and the mean pixel values and their respective standard deviations. The value " 0 " (zero) represented absence of the lesion, observed by means of the parameters described above. 


\section{Histological preparation}

After four or eight weeks, the experimental animals were anesthetized using the same protocol as used for the surgical procedures, and were sacrificed using a lethal dose of $100 \mathrm{mg} / \mathrm{kg}$ thiopental. A surgical approach was used to remove the right and left femurs. The bone was sectioned with the aid of a drill with a Carbide no. 8 bit, while preserving the lesion site with margins of $1 \mathrm{~mm}$ at each end of the defect.

The samples were fixed in $10 \%$ buffered formalin, dehydrated in a series of alcohol solutions of increasing grade, clarified using xylol and decalcified using a $50 \%$ formic acid solution. The slides were produced in the Pathology Laboratory of Hospital São Lucas, PUCRS. After complete decalcification, the femurs were embedded in paraffin and sections of thickness $5 \mu \mathrm{m}$ were cut using a microtome.

To evaluate the bone neoformation, picrosirius staining was used. This acts through precipitation of molecules of the stain Sirius red, which is deposited in parallel with the collagen molecules, thus causing an increase in the birefringence of the fibers that have conserved collagen, when observed under polarized light, thereby showing the areas of bone matrix.

After keeping the slides in a heated chamber at $60^{\circ} \mathrm{C}$ for $24 \mathrm{~h}$, they were deparaffinized and hydrated in running water. Subsequently, they were incubated in a picrosirius solution of concentration $1 \%$ for one hour, followed by washing in running water for 20 minutes.

The slides were coded in such a way that the examiner did not know which treatments they belonged to. Subsequently, the slides were photographed for analysis.

\section{Image analysis - histomorphometry}

The slides were read by the same examiner, under a Zeiss Axioskop 40 optical microscope with a $5 x$ objective lens. To capture the images, a CoolSNAPTM Pro cf camera was used (Media Cybernetics, Inc.), coupled to the microscope and to a computer, thereby producing a magnification similar to a $10 \mathrm{x}$ objective lens. Through this, the resultant images came to have a magnification of 50x. Each image was captured under normal light and polarized light, for subsequent differentiation and quantification of the area with the presence of collagen.

Two fields per slide were selected to represent the entire lesion area. Also, on the same slide, for each area with the lesion, a region adjacent to the defect, with similar dimensions, was selected to represent the normal bone (ideal: $100 \%$ bone neoformation).

After registering the images, they were analyzed using the Image ProPlus ${ }^{\circledR}$ software, version 4.5.1 (Media Cybernetics, Inc.). This made it possible, by means of counting the numbers of pixels, to measure the area in micrometers corresponding to each defect and to the normal bone. To differentiate the collagen, a measurement of the ratio of birefringent tissue per tissue unit was obtained (pixel $/ \mu \mathrm{m}$ ), using the images captured in normal light and in polarized light.

The area in micrometers was transformed into percentage neoformation by means of comparison between the area of bone tissue in the lesion and the area of normal bone tissue in the adjacent region, and this was stipulated as $100 \%$ neoformation (ideal) ${ }^{(22,23)}$.

\section{STATISTICAL ANALYSIS}

The data were expressed as means and standard deviations for variables with normal distribution. To compare values relating to the area $\left(\mathrm{mm}^{2}\right)$, longitudinal length $(\mathrm{mm})$ are area of neoformation $(\%)$ of the lesion, analysis of variance (ANOVA) was used, followed by Tukey's post-hoc test. The significance level was set at $\alpha=0.05$.

\section{RESULTS}

\section{Clinical results}

The anesthetic protocol used was shown to be effective for carrying out the surgical procedures. The medications administered after the operation were sufficient to maintain the animals' wellbeing, and no difficulty in moving the operated limbs was observed. The surgical wounds healed adequately and none of the rats presented any signs of infection or clinical complications during the study.

\section{Platelet count}

The number of platelets in the normal blood, before centrifugation to obtain PRP, was 459,000 platelets $/ \mu \mathrm{L}$, while it was $3,181,000$ platelets $/ \mu \mathrm{L}$ in PRP. The quantity of leukocytes was also higher in PRP than in normal blood $(2,800$ leukocytes/ $\mu \mathrm{L})$. The concentration of red blood cells found in PRP was 730 cells $/ \mu \mathrm{L}$, and in normal blood, 
7,420 cells $/ \mu \mathrm{L}$. The high concentrations of platelets and leukocytes and the low concentration of red blood cells confirmed that the technique used to obtain PRP was effective.

\section{Radiographic and histological results}

In the process of validation of the radiographic image analyses, the variations in length and area measurements made by the two experienced evaluators were less than the dimensions of one pixel, with $\mathrm{ICC}=0.8$, which demonstrated that the process presented high reproducibility between properly capacitated individuals.

Numerically, the PRP treatment presented lower performance than shown by the treatment with $\alpha$-TCP plus PRP. The mean area measurements of the two groups and their respective standard deviations are presented in Figure 2.

The radiographic images analyzed (Figure 3) demonstrated differences in bone constitution between the two treatments. After eight weeks, the mean for the lesion area in the PRP group was $3.23 \mathrm{~mm}^{2} \pm$ 1.46, while in the $\alpha$-TCP + PRP group, it was 1.91 $\mathrm{mm}^{2} \pm 0.93$. However, this difference did not present significance $(p=0.388)$.

In observations on the slides using an optical microscope, no signs of inflammation or necrosis were seen on the bone or adjacent tissues. In all the cases, bone tissue neoformation was observed in all areas of the surgical defect, both at the margins and in the central region.

After four week, it was observed that disorganized connective tissue had formed, permeating the areas of bone neoformation that filled the surgical cavities. After eight weeks, it was seen that the dimensions

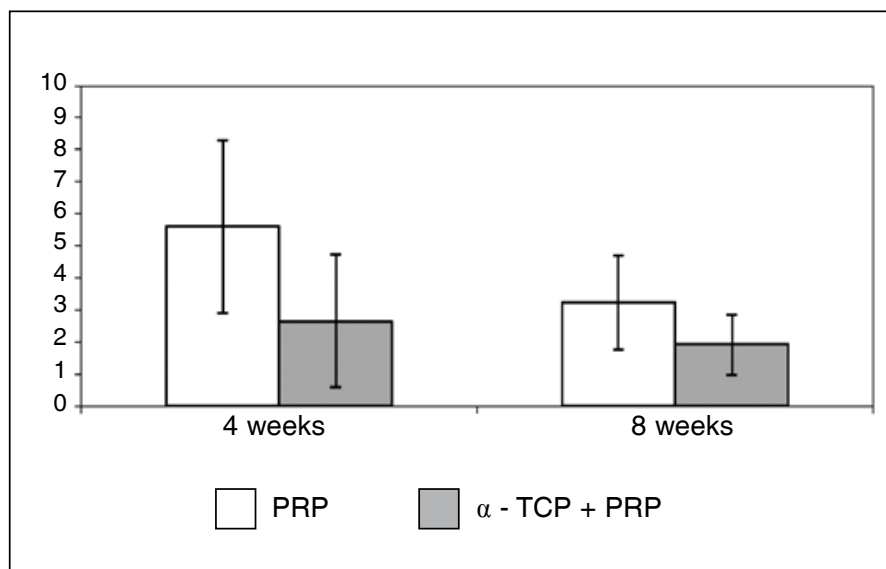

Figure 2 - Mean areas of the lesion and respective standard deviations, after four and eight weeks.

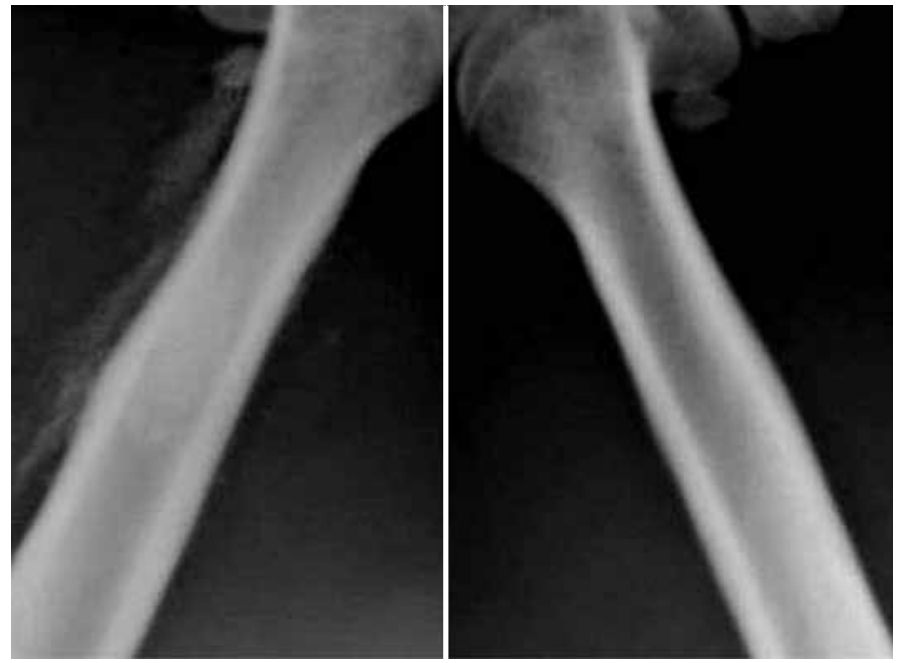

Figure 3 - Radiographic images representing the neoformed bone in the area of the lesion in the PRP group (right) and $\alpha$-TCP + PRP group (left), after eight weeks. Note that a better repair was achieved in the femur treated with $\alpha-T C P+$ PRP.

of the lesion had decreased, with a small area of organized connective tissue permeating the areas of bone neoformation that filled the surgical cavities, thus suggesting that the bone structure was undergoing remodeling. Under polarized light, the presence of organized collagen fibers could be seen (Figure 4).

In Table 1, the evolution of the bone healing in the PRP group can be seen through the means for bone neoformation. The difference between the means obtained after four and eight weeks in the group with PRP alone was significant $(p=0.015)$, and this demonstrates that after four weeks, the area of bone neoformation was still immature, in contrast with the group with $\alpha$-TCP plus PRP (Figure 4).

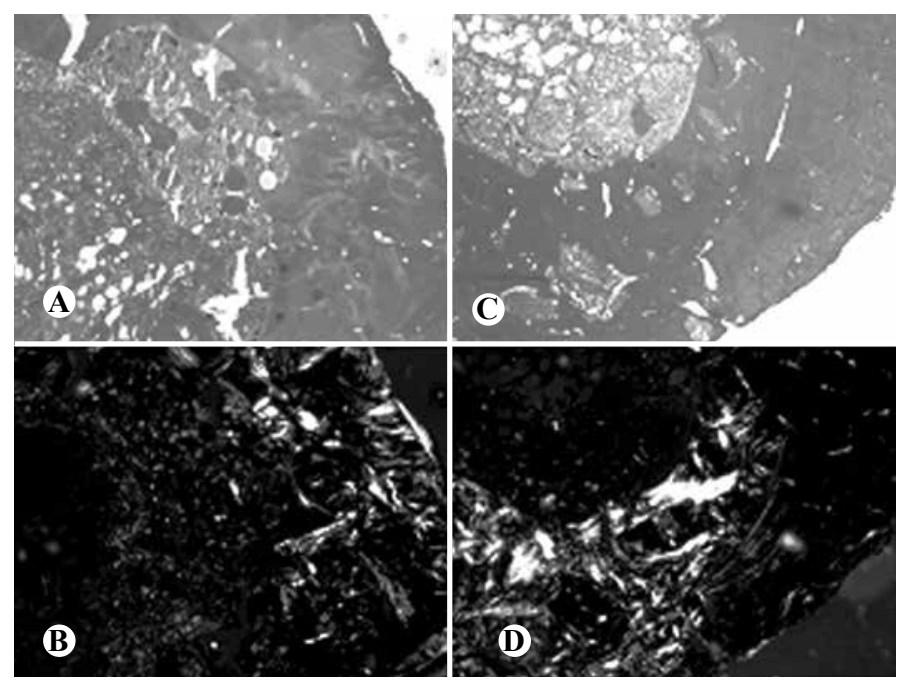

Figure 4 - PRP group ( $A$ and $B$ ) and $\alpha-T C P+P R P$ group $(C$ and $D)$, four weeks after the operation. Picrosirius red staining under normal light (upper images, $A$ and C) and under polarized light (lower images, B and D), showing that collagen was more abundant in the $\alpha$-TCP + PRP group, represented by the more lightly stained regions. Magnification 50x. 
Comparing the mean areas of bone neoformation independently of the time period, it was observed that the difference between the two treatments tended to be similar $(p=0.779)$. The means for neoformation and the respective standard deviations can be viewed in the graph of Figure 5.

Table 1 - Differences in mean areas of the lesion and the bone neoformation found after four and eight weeks.

\begin{tabular}{c|c|c|c|c}
\hline \multirow{2}{*}{ Treatment } & \multicolumn{4}{|c}{ Diference between four and eight weeks } \\
\cline { 2 - 5 } & Area $\left(\mathbf{m m}^{2}\right)$ & $\mathbf{p}$ & Neoformation (\%) & $\mathbf{p}$ \\
\hline PRP & 2,36 & 0,089 & 16 & 0,015 \\
\hline TCP+PRP & 0,74 & 0,447 & 13 & 0,067 \\
\hline Statistically significant difference for $\mathrm{p} \leq 0.05$.
\end{tabular}

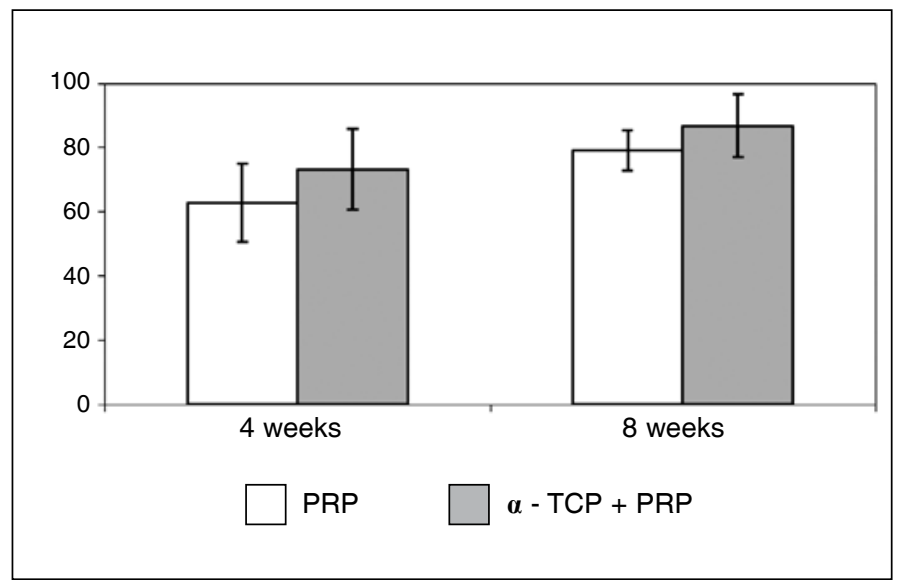

Figure 5 - Mean areas of bone neoformation and respective standard deviations, after four and eight weeks.

\section{DISCUSSION}

The most effective treatment, which is today considered to be the gold standard for repairing bone tissue damage for which recovery is difficult, is autologous grafting. Nonetheless, despite its advantages, among which histocompatibility and high osteoinductive and osteoconductive capacity can be highlighted, autologous grafts present some inconvenient features. Among their limitations are the limited quantity of donor tissue, the failure created in the graft extraction region and the difficulty in gaining acceptance from patients ${ }^{(24-27)}$.

A variety of biomaterials are constantly being investigated as bone tissue replacements, with the aim of finding an alternative that presents the same benefits as autologous grafts, but free from its disadvantages. The bone repair process involves a series of cell elements, chemical mediators and osteoconductive matrixes that regulate events at the molecular level and stimulate tissue restoration. It is believed that interactions between these parameters promote bone regeneration $^{(8,28,29)}$.

To provide support for cell growth and osteogenic differentiation, use of scaffolds produced from different biomaterials is important. In the same way, growth factors are capable of improving the osteogenic potential of scaffolds such as TCP, when applied in conjunction. Some studies have affirmed that $\alpha$-TCP cement not only is biocompatible but also is bioconductive and bioactive ${ }^{(20,25,30,31)}$. There is evidence that the growth factors obtained from PRP may regulate the reconstruction and physiological bone remodeling, and are a powerful form of treatment in lesion repair ${ }^{(10,18,32-35)}$. In the light of these precepts, combined application of $\alpha$-TCP cement and PRP seems to fit the ideal properties characterizing these interactions.

In the present study, the platelet concentration in the PRP from the rats was seven times greater than the level in normal blood (PRP $=3,181,000$ platelets $/ \mu L)$. The therapeutic concentration of platelets in PRP that is considered ideal in humans is approximately 1,000,000/ $\mu \mathrm{L}^{(15)}$. Trowbridge et $\mathrm{l}^{(36)}$ affirmed that the mean quantity of platelets in rats is significantly higher than in humans, while the mean volume of platelets is significantly lower than in humans. Thus, there are biological differences between species that need to be taken into consideration. Only the protocols for obtaining human PRP are standardized, along with the ideal platelet concentrations and growth factor levels. Thus, the therapeutic levels of platelet concentrations and growth factor levels in animals still need to be defined.

In the radiographic analysis presented here, it was observed that the performance of the group treated with PRP alone was numerically lower. However, the difference found between the treatments was not significant at either of the times analyzed (Figure 2). The treatment with $\alpha$-TCP plus PRP presented smaller mean lesion areas after four and eight weeks, which indicates better bone repair.

The results obtained demonstrated that PRP stimulates bone remodeling, in a similar manner to results found in the literature, in which PRP was applied to the same species ${ }^{(37)}$. All the defects in both groups evaluated (PRP alone and $\alpha$-TCP + PRP) presented remodeled bone after eight weeks. The histological data suggest that application of $\alpha$-TCP cement and PRP together may produce an early osteogenic effect, 
given that after four weeks, the mean for the latter was $73.3 \% \pm 12.7$, i.e. greater than for the PRP group. After eight weeks, the mean for the combined application was $86.7 \% \pm 9.8$, i.e. 13 percentage points greater than after four weeks, but this difference was not significant (Table 1). Studies have proven that combining PRP with biomaterials optimizes and accelerates the bone tissue regeneration process ${ }^{(38)}$.

The histological analyses also demonstrated that there was no inflammatory response or necrosis in any of the animals, and this is concordant with studies that aimed to assess the biocompatibility of $\alpha$-TCP cement $^{(39,40)}$. Another possible explanation for the absence of inflammation or bone necrosis is that saline solution was used to constantly irrigate the surgical field while the defects were being created, and that both the cement and the surgical materials used in all the procedures had been sterilized.

According to Marx et $\mathrm{al}^{(10)}$, PRP has an influence on cells. Therefore, when used in combination with synthetic bone substitutes, a synergic effect on bone neoformation should be presented. However, the benefits from PRP depend on the quantity of osteoprogenitor cells present at the implantation site and on the action of the growth factors released by the platelets ${ }^{(41)}$.

In the histomorphometric analysis, bone growth around the particles of $\alpha$-TCP cement was observed, along with the presence of collagen. The bioactivity and osteoconductivity of the $\alpha$-TCP granules may favor bone regeneration. It is known that partial degradation of calcium phosphate cements causes release of calcium and phosphate ions into the bone microenvironment, which over the long term promotes mineralization and increases bone neoformation ${ }^{(42)}$. Kihara et $\mathrm{al}^{(43)}$ observed bone neoformation on

\section{REFERÊNCIAS}

1. Lysaght MJ, Nguy NA, Sullivan K. An economic survey of the emerging tissue engineering industry. Tissue Eng. 1998;4(3):231-8.

2. Lidgren $\mathrm{L}$. The Bone and Joint Decade and the global economic and healthcare burden of musculoskeletal disease. J Rheumatol Suppl. 2003;67:4-5.

3. Remedios A. Bone and bone healing. Vet Clin North Am Small Anim Pract. 1999;29(5):1029-44.

4. Cancedda R, Giannoni P, Mastrogiacomo M. A tissue engineering approach to bone repair in large animal models and in clinical practice. Biomaterials. 2007;28(29):4240-50.

5. Chu TM, Warden SJ, Turner CH, Stewart RL. Segmental bone regeneration using a load-bearing biodegradable carrier of bone morphogenetic protein-2. Biomaterials. 2007;28(3):459-67.

6. Hollinger JO, Brekke J, Gruskin E, Lee D. Role of bone substitutes. Clin Orthop Relat Res. 1996;(324):55-65.

7. Hench LL. Biomaterials: a forecast for the future. Biomaterials. 1998; 19(16):1419-23. the surface and interior of $\alpha$-TCP particles when this cement was applied to bone defects in rabbits, similarly to the present study. These data provide support for the affirmation that $\alpha$-TCP cement is an osteoconductive material, thus enabling bone matrix development from this.

For bone substitutes to become properly integrated with the bone tissue, it is important that their shape should be preserved. In carrying out the present study, some difficulty was found in handling $\alpha$-TCP cement in relation to its solubility, which impairs its adhesion to the surgical site because of the presence of large quantities of fluid structures (blood and bone marrow). However, this limitation was controlled by means of adequate aspiration and a dry surgical field, in order to avoid displacement and extravasation of the cement after it was applied.

\section{CONCLUSION}

The results from this study suggest that treatment with $\alpha$-TCP cement combined with PRP did not present any statistically significant different in relation to use of PRP alone. With regard to the effect of the two treatments on osteogenesis in cavity defects in rats' femurs, the data indicated that there may be any early effect when PRP and $\alpha$-TCP cement are applied together, such that the osteoinductive activity may be boosted.

\section{ACKNOWLEDGEMENT}

The authors thank Prof. Dr. Vinicius Duval, Coordinator of the Pathology Laboratory of Hospital São Lucas, PUCRS, for all his support and knowledge during the histological evaluations.
8. Giannoudis PV, Einhorn TA, Marsh D. Fracture healing: a harmony of optimal biology and optimal fixation? Injury. 2007;38(Suppl 4):S1-2.

9. Anitua E. Plasma rich in growth factors: preliminary results of use in the preparation of future sites for implants. Int J Oral Maxillofac Implants. 1999;14(4):529-35.

10. Marx RE, Carlson ER, Eichstaedt RM, Schimmele SR, Strauss JE, Georgeff KR. Platelet-rich plasma: Growth factor enhancement for bone grafts. Oral Surg Oral Med Oral Pathol Oral Radiol Endod. 1998;85(6):638-46.

11. Okuda K, Kawase T, Momose M, Murata M, Saito $Y$, Suzuki H, et al. Platelet-rich plasma contains high levels of platelet-derived growth factor and transforming growth factor-beta and modulates the proliferation of periodontally related cells in vitro. J Periodontol. 2003;74(6):849-57.

12. Marx RE. Platelet-rich plasma (PRP): what is PRP and what is not PRP? Implant Dent. 2001;10(4):225-8.

13. Anitua E, Andia I, Ardanza B, Nurden P, Nurden AT. Autologous platelets as a source of proteins for healing and tissue regeneration. Thromb Haemost. 2004; 91(1):4-15. 
14. Gandhi A, Doumas C, O'Connor JP, Parsons JR, Lin SS. The effects of local platelet rich plasma delivery on diabetic fracture healing. Bone. 2006;38(4):540-6.

15. Marx RE. Platelet-rich plasma: evidence to support its use. J Oral Maxillofac Surg. 2004;62(4):489-96.

16. Yamamiya K, Okuda K, Kawase T, Hata K, Wolff LF, Yoshie H. Tissue-engineered cultured periosteum used with platelet-rich plasma and hydroxyapatite in treating human osseous defects. J Periodontol. 2008;79(5):811-8.

17. Sammartino G, Tia M, Gentile E, Marenzi G, Claudio PP. Platelet-rich plasma and resorbable membrane for prevention of periodontal defects after deeply impacted lower third molar extraction. J Oral Maxillofac Surg. 2009;67(11):2369-73.

18. Bi L, Cheng W, Fan H, Pei G. Reconstruction of goat tibial defects using an injectable tricalcium phosphate/chitosan in combination with autologous platelet-rich plasma. Biomaterials. 2010;31(12):3201-11.

19. Rossi Junior R, Negreiros RM, Elias FM, Jorge WA. Utilização de plasma rico em plaquetas em enxertos ósseos para reparação de defeitos ósseos. Rev Odonto Univ Cidade São Paulo. 2008;20(3):295-300.

20. dos Santos L. Desenvolvimento de cimento de fosfato de cálcio reforçado por fibras para uso na área médico-odontológica [tese]. Campinas: Universidade Estadual de Campinas; 2002.

21. Moreira ASB, Pastoreli MT, Damasceno LHF, Defino HLA. Estudo experimental da influência das dimensões dos grânulos de hidroxiapatita na integração óssea. Acta Ortop Bras. 2003;11(4):240-50.

22. Gundersen HJ, Bendtsen TF, Korbo L, Marcussen N, Møller A, Nielsen K, et al. Some new, simple and efficient stereological methods and their use in pathological research and diagnosis. APMIS. 1988;96(5):379-94.

23. Stein RS, Braga Silva J, Silva VD. Estudo comparativo da neoformação óssea utilizando-se o enxerto autógeno e três substitutos: defeitos ósseos em ratos. Rev Bras Ortop. 2009;44(4):330-5

24. Arrington ED, Smith WJ, Chambers HG, Bucknell AL, Davino NA. Complications of iliac crest bone graft harvesting. Clin Orthop Relat Res. 1996;(329):300-9.

25. Giannoudis PV, Dinopoulos H, Tsiridis E. Bone substitutes: an update. Injury. 2005;36(Suppl 3):S20-7.

26. Pollock R, Alcelik I, Bhatia C, Chuter G, Lingutla K, Budithi C, et al. Donor site morbidity following iliac crest bone harvesting for cervical fusion: a comparison between minimally invasive and open techniques. Eur Spine J. 2008;17(6):845-52.

27. Seiler JG 3rd, Johnson J. Iliac crest autogenous bone grafting: donor site complications. J South Orthop Assoc. 2000;9(2):91-7.

28. Laurencin CT, Einhorn TA, Lyons K. Fracture repair: challenges and opportunities. J Bone Joint Surg Am. 2008;90(Suppl 1):1-2.

29. Pountos I, Georgouli T, Blokhuis TJ, Pape HC, Giannoudis PV. Pharmacological agents and impairment of fracture healing: what is the evidence? Injury. 2008;39(4):384-94.
30. Knabe C, Stiller M, Berger G, Reif D, Gildenhaar R, Howlett CR, et al. The effect of bioactive glass ceramics on the expression of bone-related genes and proteins in vitro. Clin Oral Implants Res. 2005;16(1):119-27.

31. Valerio P, Pereira MM, Goes AM, Leite MF. The effect of ionic products from bioactive glass dissolution on osteoblast proliferation and collagen production. Biomaterials. 2004;25(15):2941-8.

32. Kasten P, Vogel J, Geiger F, Niemeyer P, Luginbühl R, Szalay K. The effect of platelet-rich plasma on healing in critical-size long-bone defects. Biomaterials. 2008;29(29):3983-92.

33. Döri F, Kovács V, Arweiler NB, Huszár T, Gera I, Nikolidakis D, et al. Effect of platelet-rich plasma on the healing of intrabony defects treated with an anorganic bovine bone mineral: a pilot study. J Periodontol. 2009;80(10):1599-605.

34. Nagata MJ, Melo LG, Messora MR, Bomfim SR, Fucini SE, Garcia VG, ET $A L$. Effect of platelet-rich plasma on bone healing of autogenous bone grafts in critical-size defects. J Clin Periodontol. 2009;36(9):775-83.

35. Findikcioglu K, Findikcioglu F, Yavuzer R, Elmas C, Atabay K. Effect of platelet-rich plasma and fibrin glue on healing of critical-size calvarial bone defects. $J$ Craniofac Surg. 2009;20(1):34-40.

36. Trowbridge EA, Martin JF, Slater DN, Kishk YT, Warren CW, Harley PJ, et al. The origin of platelet count and volume. Clin Phys Physiol Meas. 1984;5(3):145-70.

37. Messora MR, Nagata MJ, Mariano RC, Dornelles RC, Bomfim SR, Fucini $\mathrm{SE}$, et al. Bone healing in critical-size defects treated with platelet-rich plasma: a histologic and histometric study in rat calvaria. J Periodontal Res. 2008;43(2):217-23.

38. Zhang YD, Wang G, Sun Y, Zhang CQ. Combination of platelet-rich plasma with degradable bioactive borate glass for segmental bone defect repair. Acta Orthop Belg. 2011;77(1):110-5.

39. dos Santos LA, Carrodéguas RG, Rogero SO, Higa OZ, Boschi AO, de Arruda AC. Alpha-tricalcium phosphate cement: "in vitro" cytotoxicity. Biomaterials. 2002;23(9):2035-42.

40. Biancon Filho LA, Primo BT, Gassen HT, Fontanella VR, Silva AN Jr. Evaluation of optical density of bone defects filled with calcium phosphate cement and bioactive glass in rats. Acta Cir Bras. 2011;26(1):2-6.

41. Pryor ME, Polimeni G, Koo KT, Hartman MJ, Gross H, April M, et al. Analysis of rat calvaria defects implanted with a platelet-rich plasma preparation: histologic and histometric observations. J Clin Periodontol. 2005;32(9):966-72.

42. LeGeros RZ. Calcium phosphate-based osteoinductive materials. Chem Rev. 2008;108(11):4742-53.

43. Kihara $\mathrm{H}$, Shiota $\mathrm{M}$, Yamashita $\mathrm{Y}$, Kasugai S. Biodegradation process of alpha-TCP particles and new bone formation in a rabbit cranial defect model. $J$ Biomed Mater Res B Appl Biomater. 2006;79(2):284-91. 